Original Research

\title{
The Effect of Health Promotion Intervention on Anemia Prevention Behavior and Haemoglobin Level in Pregnant Women: Based on Health Promotion Model and Self- Determination Theory
}

\author{
Mira Triharini' ${ }^{1}$ Agus Sulistyono², Merryana Adriani' ${ }^{3}$, and Shrimarti Rukmini Devy ${ }^{3}$ \\ ${ }^{1}$ Faculty of Nursing, Universitas Airlangga, Indonesia \\ 2 Dr. Soetomo General Hospital Surabaya, Indonesia \\ ${ }^{3}$ Faculty of Public Health, Universitas Airlangga, Indonesia
}

\begin{abstract}
Introduction: Anemia during pregnancy has an impact on pregnancy and fetus. Pregnant women who have low iron status can affect the development of nerves and behavior of children. Low self-determination in pregnant women will affect the commitment to prevent anemia. The objective of the study was to analyze the effect of Health Promotion Model and Self Determination Theory Based Intervention on anemia prevention behaviors and hemoglobin level in pregnant mothers.
\end{abstract}

Methods: This research was a quasi-experiment research with a pre- and posttest using a control group design. The samples were 30 pregnant women who did antenatal care in Community Health Center of Tanah Kali Kedinding Surabaya. Intervention through health education about anemia in pregnancy, family support and self-determination was held 3 times consisting of 1 meeting with health professionals, 1 meeting with pregnant mothers, and 1 meeting with pregnant women and their families through home visits. Data were collected using questionnaires that consist of adherence to iron supplementation and behavioral prevention of intestinal worms, food recall in $2 \times 24$ hours, and laboratory test for hemoglobin level. Paired T-test and Independent T-test was used to analyze data in this study.

Results: There was an effect of Health Promotion Model and Self Determination Theory Based Intervention to anemia prevention behaviors and hemoglobin level $(\mathrm{p}=0.013 ; \mathrm{p}=0.040)$.

Conclusion: Health workers can use Health Promotion Model and Self Determination Theory Based Intervention to improve anemia prevention behavior.

\section{ARTICLE HISTORY}

Received: September, 102019 Accepted: December, 42019

\section{KEYWORDS}

anemia in pregnancy; behavior; self-determination; health promotion; prevention

\section{CONTACT}

Mira Triharini

$\bowtie$ mira-t@fkp.unair.ac.id

$\doteq$ Faculty of Nursing,

Universitas Airlangga, Indonesia

Cite this as: Triharini, M., Sulistyono, A., Adriani, Merryana., Devy, S., R. (2019). The Effect of Health Promotion Intervention on Anemia Prevention Behavior and Haemoglobin Level in Pregnant Women: Based on Health Promotion Model and Self-Determination Theory. Jurnal Ners, 14(1),92-100. doi:http://dx.doi.org/10.20473/jn.v14i1.15213

\section{INTRODUCTION}

Iron deficiency anemia is a major nutritional problem that occurs in many developing countries. In current study in Pakistan showed 65.4\% pregnant women were anemic. On the basis of $\mathrm{Hb}$ level, $6.4 \%$ were severely anemic, $19.2 \%$ were moderately and $39.8 \%$ were mildly anemic (Hameed et al., 2018). From the data of the Indonesian Basic Health Research in 2018 found that $48.9 \%$ of pregnant women in Indonesia were anemic (Ministry of Health, 2018). Anemia is considered to be one of huge public health challenge as population studies find that anemia prevalence is at $5.0 \%$ or higher (WHO, 2008). Anemia during pregnancy may cause health problems in pregnant women and fetuses (Huang, Purvarshi, Wang, Zhong, \& Tang, 2015). Anemia is associated with the incidence of low birth weight in newborns (Aboye, Berhe, Birhane, \& Gerensea, 2018). The behavior of pregnant women in the prevention of 
anemia needs to be done through health promotion by looking at various internal and external factors of pregnant women. The Health Promotion Model (HPM) as a nursing theory may be used as a theoretical basis to help patients conduct healthy behaviors (Pender, 2011). Physical and psychological changes experienced by mothers during pregnancy will have an impact on their ability to make efforts to prevent anemia, so a behavioral model for prevention of anemia with self-determination is needed that forms a high commitment. Various health promotion efforts that have been carried out are expected to provide behavioral changes in pregnant mothers will last longer, if they are committed and have high intrinsic motivation from pregnant women themselves.

There are various factors that affect the incidence of anemia in pregnant mothers, namely inadequate antenatal care, close birth spacing, and poor nutrition (Singal, Setia, Taneja, \& Singal, 2018).The current high incidence of anemia may be influenced by the low behavior of mothers in preventing anemia, such as do not take the iron supplement tablets regularly. Based on data from the Indonesian Basic Health Research in 2018, 61.9\% of pregnant women in Indonesia consumed fewer than 90 iron tablets (Ministry of Health, 2018). Many pregnant women do not adhere in taking iron tablets because of the belief that iron tablets only need to be taken when they have health complaints. This was supported by studies of factors that influenced the adherence to iron tablets in pregnant women were the level of education and knowledge about anemia and iron tablets (Taye, Abeje, \& Mekonen, 2015). Other studies showed that perceptions of benefits, barriers and family support affected maternal compliance in taking iron tablets (Triharini et al., 2018).

HPM is multidimensional which has an impact on health, individuals, environment and nursing. HPM also states that health behavior requires commitment based on cognition and affection factors. The concept of this model explain the uniqueness of individuals, families, and communities, as it explain the perceived benefits, perceived barrier and perceived self efficacy may influence individual's health behavior (Pender, 2011). This theory has been widely used in various research areas, for example a study had showed perceived benefits, perceived self efficacy, interpersonal influences, commitment to a plan of action have an effect on nutritional intake (Dehdari, Rahimi, Aryaeian, \& Gohari, 2013). Commitment of pregnant women in anemia prevention behavior would be better if the mother has a strong selfdetermination. With a strong commitment, pregnant women will be able to overcome the barriers in preventing anemia.

In accordance with the Self Determination Theory (SDT), the behavior is expected to be able to last longer when the patient is able to internalize the value and achieve satisfaction with the fulfillment of three psychological needs in health services, autonomy, competence, and relatedness (Patrick \& Williams, 2012). SDT has been widely used in research to increase commitment and health behavior. Satisfaction with fulfilling psychological needs improves health behaviors for eating healthy foods (Ryan, Patrick, Deci, \& Williams, 2008).

In an effort to increase the commitment of pregnant women to overcome the problem of preventing anemia, an intervention in the form of health education is needed based on the use of the HPM theory and SDT. This intervention is comprehensive because it involves several parties, who are expected to increase the commitment of pregnant mothers, including health professionals, pregnant mothers, families, and groups of pregnant mothers. The HPM and STD model emphasizes several aspects, namely (1) the cognitive aspects of pregnant women, which include increasing perceived benefits, reducing the perceived barrier, and increasing self-efficacy; (2) the increase of environmental support, which includes health professionals, families and groups of pregnant mothers; (3) the increase of self-motivation for preventing anemia; and (4) the increase of the goal of pregnancy. There is no study conducted to explain HPM and SDT-based intervention to improve anemia prevention behavior. Hence, this study was aimed to explain the effectiveness of interventions using HPM and SDT on the prevention behavior of anemia and hemoglobin levels in pregnant women.

\section{MATERIALS AND METHODS}

This research used a quasi-experimental design with two groups, pre-test, and post-test, which were conducted from January to March 2018.

The population was pregnant women attending antenatal care at Puskesmas (the Community Health Center) of Tanah kali Kedinding in Surabaya, East Java, Indonesia. The inclusion criteria were pregnant women who were receiving iron supplementation from the Community Health Center. The exclusion criteria were those who did not have anemia based on an examination of the Community Health Center and with complication of diseases that required specific medical treatment. The samples that met the inclusion criteria were 30 mothers with 15 mothers for each group.

Data were collected using questionnaires, food recall in 2x24 hours, and hemoglobin level examination using the cyanmethemoglobin method. Qualified nutritionists conducted the food recall in pregnant women to carry out data collection on consumption patterns. Nutrition laboratory staff at Universitas Airlangga Surabaya carried out hemoglobin level examination using the cyanmethemoglobin method.

The questionnaires were focused on sociodemographic characteristics, and anemia prevention behavior. The sociodemographic characteristics of questions asked about age, parity, 
education and income. The questions about anemia prevention behavior consisted of adherence to iron supplementation and prevention of intestinal worms. The questionnaires were developed by researchers with items based on the theory of prevention of maternal anemia and the health-promotion model (HPM) (Pender, 2011; Sharma \& Shankar, 2010). While preparing the questionnaire contents, the researchers were assisted by two experienced nurses in the field of maternity nursing. Translation was accomplished by a qualified translator from Indonesia. Before being used in data collection, the compiled questionnaires had been tested for validity and reliability on 20 pregnant women who attended antenatal care at Community Health Center Keputih Surabaya.

Data collection on adequacy of energy, carbohydrates, protein, vitamin C, and iron of pregnant mothers was based on their age and gestational age. Measurements were made with a questionnaire with a $2 \times 24$ hour food recall method the results of which were expressed in calories, grams and mg, compared with the Recommended Dietary Allowance (RDA) (Ministry of Health, 2013). The questions on adherence to iron supplementation focused on four items: regularity, time, reducing and increasing absorption process. The questionnaire consisted of four questions. Each item was converted into a Likert scale with the following options: always, often, sometimes, rarely and never. The total scores for this section were in the range of 4-20, with higher scores indicating higher levels of adherence to iron supplementation. The validity of the questionnaire on adherence to iron supplementation had a Cronbach's $\alpha$ of 0.761

The questionnaire on behavioral prevention of intestinal worms consisted of two items: personal hygiene and environmental hygiene. Each item was converted into a Likert scale with the following options: always, often, sometimes, rarely and never. The total scores for this section were in the range of 6-24, with higher score indicating higher levels of behavioral prevention of intestinal worms. The validity and reliability test of the questionnaire on prevention of intestinal worms had a Cronbach's $\alpha$ of 0.831 .

Paired T-test was used to examine the differences between the pre-test and post-test scores for both the intervention group and control group. Independent ttest was used to analyze the effect of Health Promotion Model and Self Determination Theory Based Intervention on anemia prevention behavior and hemoglobin level. Descriptive statistics, including frequency, percentage, mean, and standard deviation, were used to describe sociodemographic characteristics. In all statistical analyses, a p-value of $<0.05$ was considered significant. All data were analyzed using SPSS software.

After selecting respondents based on inclusion criteria, the researchers conducted a health education intervention on the topics of anemia prevention, selfdetermination and family support. Anemia prevention material discusses the definition of anemia, the causes of anemia, the influence of anemia on pregnancy, and ways to prevent anemia, which includes procedures for taking iron tablets, dietary regulation, and prevention of intestinal worms. Selfdetermination material discusses three psychological needs of pregnant women that need to be fulfilled and self-motivation in preventing anemia. Family support material to prevent anemia includes the benefits of family support for pregnant women, forms of support given to pregnant women, and family support for pregnant women to have a strong determination in preventing anemia.

Intervention activities were held three times consisting of one meeting with health professionals, one meeting with pregnant mothers, and one meeting with pregnant women and their families through home visits. The first meeting was held for 1 x 60 minutes targeting health professionals with anemia health promotion to pregnant mothers. This meeting aimed to improve the understanding of health professionals about intervention. In this meeting, the researchers discussed the model of health education that needed to be provided based on HBM and selfdetermination, which aimed to increase the satisfaction of pregnant women in terms of psychological needs, including autonomy, competence, and relatedness. At the end of the session, the researchers gave the module to the health professionals.

The second meeting was held for 1 x 60 minutes targeting the pregnant women in groups. This meeting aimed to improve the perceived benefit and reduce perceived barriers according to the HPM theory, to improve the orientation and goals of maternal pregnancy in implementing anemia prevention behaviors according to the theory of selfdetermination, and to support the groups of pregnant mothers. The researchers conveyed material about the concept of anemia of pregnancy, ways to prevent anemia through nutrition, adherence with iron supplementation and prevention of intestinal worms, the role of support for pregnant women groups, and the concept of self-determination. The researchers applied the concept of communication by paying attention to fulfilling the psychological needs of the mother according to the SDT theory, which included the needs of autonomy, competence, and relatedness. At the end of the meeting session, pregnant women were asked to plan the actions to be carried out. They were also given a form to record the adherence to iron supplementation. The researchers provided leaflets about anemia in pregnancy. In a group meeting of pregnant women there was a meeting between multigravida with primigravida mothers. Researchers provided an opportunity for multigravida mothers to convey previous pregnancy experiences in carrying out anemia prevention behaviors and as role models for other pregnant women. The positive thing expressed by mothers is trying to keep taking iron tablets according to the advice of the midwife so that the baby is healthy, even 
though sometimes they feel bored and nauseous. Mothers stated that they were very happy when their labor was smooth and the baby was in good health. Primigravida pregnant women can study the past experiences of other pregnant women and achieve the motivation and goals of their pregnancy.

The third meeting was held for 1 x 60 minutes targeting the family members of pregnant women who lived at home. The purpose of this meeting was to increase family support to pregnant women in an effort to prevent anemia. The researchers delivered material about the concept of anemia, ways to prevent anemia, and the role of family support to pregnant mothers. The researchers also looked at the form of the results of record adherence to iron supplementation that had been made by pregnant women and discussed the obstacles that existed in carrying out prevention for anemia.

Post-test data collection was carried out after three months of intervention using questionnaires that consisted of adherence to iron supplementation and behavioral prevention of intestinal worms, food recall in $2 \times 24$ hours, and laboratory test for hemoglobin level.

Sampling was conducted after ethical approval from the health research ethics committee of the Faculty of Public Health, Airlangga University in Surabaya (No 123-KEPK).

\section{RESULTS}

Table 1 shows that the majority of respondents were aged 25-35 years, both in the intervention group $(66.7 \%)$ and the control group $(53.3 \%)$. The majority of respondents had one parity in the intervention group $(40.0 \%)$ and nullipara in the control group $(46.7 \%)$. More than half of the intervention group (88.0\%) and control groups (53.3\%) had income of < 3 million rupiahs. More than half of the intervention group $(60.0 \%)$ and the control group (79.9\%) had secondary education levels.

Table 2 shows that there is an increased mean score after an intervention in the intervention group on the nutritional adequacy (15.67 \pm 4.49$)$, adherence to iron supplementation (21.47 \pm 1.19$)$, and prevention of intestinal worms $(29.93 \pm 0.26)$. In the intervention group, the mean difference in nutritional adequacy score was 4.14 , the difference in adherence to iron supplementation score was 1.20 , and the difference in prevention of intestinal worms score was 0.40 . The results of the t-test showed that $p$ value $<0.05$, indicating that there were significant differences of nutritional adequacy, adherence to iron supplementation and prevention of intestinal worms between before and after the intervention.

Table 3 shows that there is an increased mean score after an intervention in the intervention group on anemia prevention behavior $(67.07 \pm 4.74)$ and hemoglobin level $(12.87 \pm 1.04)$. In the intervention group, the mean difference in anemia prevention behavior score was 5.74. The results of the t-test showed that $\mathrm{p}$ value $0.004<0.05$, indicating that there were significant differences of anemia prevention behavior between before and after the intervention. Data show an increased score in anemia prevention behavior between before and after intervention in the intervention group. The results of the independent t-test between the intervention and control groups after the intervention obtained p value $0.013<0.05$, which means that intervention influenced the anemia prevention behavior.

Table 3 shows that, in the intervention group, the mean difference in hemoglobin level score was 0.68 . The results of the t-test showed that $p$ value $0.025<$ 0.05 , meaning that there were significant differences of hemoglobin level behavior between before and after the intervention. Data show an increase in hemoglobin between before and after the intervention. The results of the independent t-test between the intervention and control groups after the intervention obtained $\mathrm{p}$ value $0.040<0.05$, which means that intervention influenced the hemoglobin level.

\section{DISCUSSION}

Interventions based on HPM and SDT influenced the anemia prevention behavior and hemoglobin level. Anemia prevention behavior was measured by three indicators including: (1) Consumption of energy, carbohydrates, protein, vitamin C, iron; (2) Adherence to iron supplementation (3) Intestinal worm prevention behavior. In this study, the results show that, after interventions based on HPM and SDT, there was an increase in the mean score on anemia prevention behavior and hemoglobin levels in the intervention group. There was a significant difference in anemia prevention behavior and hemoglobin level between before and after the intervention. This intervention may increase the self-determination of pregnant women so that they have a strong commitment to conduct behaviors to prevent anemia properly.

Pre-test scores on nutritional adequacy showed low results because there are still many pregnant women who are still in the deficit category based on food recall results. The cause of this is possible because there is still a lack of knowledge of mothers about the importance of adequate nutrition during pregnancy, so that pregnant women do not pay attention to the adequacy of their daily nutritional needs. This is supported by the number of respondents who have elementary education. Economic factors also affect the ability of mothers to meet nutritional adequacy, where most respondents have an income of less than 3 million rupiah. This is supported by other research that shows there are many factors that affect the nutrition of pregnant women. Socioeconomic factors (education level, employment status, monthly income, household 
Table 1.Distribution of both groups regarding their sociodemographic characteristics

\begin{tabular}{|c|c|c|c|c|c|c|}
\hline \multirow[t]{2}{*}{ No } & \multirow[t]{2}{*}{ Variable } & \multicolumn{2}{|c|}{ Intervention } & \multicolumn{2}{|c|}{ Control } & \multirow[b]{2}{*}{ P value } \\
\hline & & $\mathbf{n}$ & $\%$ & $\mathbf{n}$ & $\%$ & \\
\hline \multirow[t]{4}{*}{1} & Age (yrs) & & & & & 0,156 \\
\hline & $<25$ & 4 & 26.7 & 4 & 26.7 & \\
\hline & $25-35$ & 10 & 66.7 & 8 & 53.3 & \\
\hline & $>35$ & 1 & 6.7 & 3 & 20.0 & \\
\hline \multirow[t]{5}{*}{2} & Parity & & & & & 0,092 \\
\hline & 0 & 5 & 33,33 & 7 & 46.7 & \\
\hline & 1 & 6 & 40,00 & 4 & 26.7 & \\
\hline & 2 & 2 & 13.3 & 4 & 26.7 & \\
\hline & 3 & 2 & 13.3 & - & & \\
\hline \multirow[t]{3}{*}{3} & Income (Rupiah)a & & & & & 0,275 \\
\hline & $<3$ million & 12 & 80.0 & 8 & 53.3 & \\
\hline & $\geq 3$ million & 3 & 20.0 & 7 & 46.7 & \\
\hline \multirow[t]{4}{*}{4} & Education level & & & & & 0,455 \\
\hline & Elementary & 5 & 33.3 & 3 & 20,1 & \\
\hline & Secondary & 9 & 60.0 & 12 & 79. 9 & \\
\hline & University & 1 & 6.7 & - & & \\
\hline
\end{tabular}

a13.500 Rupiahs equal to 1 US Dollar (US\$)

Table 2. Distribution of intervention and control group regarding indicator of anemia prevention behavior in pre-post intervention

\begin{tabular}{llcccc}
\hline $\begin{array}{l}\text { Anemia prevention } \\
\text { behavior }\end{array}$ & Group & $\begin{array}{c}\text { pre test } \\
\text { (mean } \pm \text { SD) }\end{array}$ & $\begin{array}{c}\text { post test } \\
\text { (mean } \pm \text { SD) }\end{array}$ & $\begin{array}{l}\text { Mean } \\
\text { differences }\end{array}$ & P value \\
\hline Nutritional adequacy & Intervention & $11.53 \pm 5.33$ & $15.67 \pm 4.49$ & 4.14 & 0.019 \\
\cline { 2 - 7 } & Control & $14.73 \pm 4.18$ & $15.93 \pm 3.41$ & 1.20 & 0.389 \\
\hline $\begin{array}{l}\text { Adherence to iron } \\
\text { supplementation }\end{array}$ & Intervention & $20.27 \pm 0.96$ & $21.47 \pm 1.19$ & 1.20 & 0.003 \\
\cline { 2 - 7 } $\begin{array}{l}\text { Prevention of intestinal } \\
\text { worms }\end{array}$ & Control & $19.20 \pm 2.54$ & $18.87 \pm 1.41$ & -0.33 & 0.642 \\
\cline { 2 - 7 } & Intervention & $29.53 \pm 0.52$ & $29.93 \pm 0.26$ & 0.40 & 0.009 \\
\hline
\end{tabular}

Table 2. Distribution of intervention and control group regarding indicator of anemia prevention behavior in pre-post intervention

\begin{tabular}{llcccc}
\hline $\begin{array}{l}\text { Anemia prevention } \\
\text { behavior }\end{array}$ & Group & $\begin{array}{c}\text { pre test } \\
\text { (mean } \pm \text { SD) }\end{array}$ & $\begin{array}{c}\text { post test } \\
\text { (mean } \pm \text { SD) }\end{array}$ & $\begin{array}{l}\text { Mean } \\
\text { differences }\end{array}$ & P value \\
\hline Nutritional adequacy & Intervention & $11.53 \pm 5.33$ & $15.67 \pm 4.49$ & 4.14 & 0.019 \\
\cline { 2 - 6 } & Control & $14.73 \pm 4.18$ & $15.93 \pm 3.41$ & 1.20 & 0.389 \\
\hline $\begin{array}{l}\text { Adherence to iron } \\
\text { supplementation }\end{array}$ & Intervention & $20.27 \pm 0.96$ & $21.47 \pm 1.19$ & 1.20 & 0.003 \\
\cline { 2 - 7 } $\begin{array}{l}\text { Prevention of intestinal } \\
\text { worms }\end{array}$ & Control & $19.20 \pm 2.54$ & $18.87 \pm 1.41$ & -0.33 & 0.642 \\
\cline { 2 - 7 } & Intervention & $29.53 \pm 0.52$ & $29.93 \pm 0.26$ & 0.40 & 0.009 \\
\hline
\end{tabular}

assets and land ownership) have been shown to influence dietary diversity (Kiboi, Kimiywe, \& Chege, 2017). There are still many pregnant women with insufficient nutrition. The result revealed that the caloric intake was below the RDA (85\%), while calcium, iron, vitamins $\mathrm{A}, \mathrm{E}, \mathrm{C}$ and folate intake were respectively 28\%, 47\%, 25\%, 9\% 31\% and $44 \%$ (Yetunde \& Olubukunola, 2015). The presence of deficits in adequate iron was also caused by the irregularity of the mother in taking iron tablets. Iron requirements during pregnancy were not enough to only be filled with daily food, but also must be added with iron tablet supplements. In this study, it was found that some pregnant women do not regularly take iron tablets because they feel side effects after taking them, forget and get bored because you have to drink them every day.

The results showed that there was an increase in post-test scores on the adequacy of nutrition in the intervention group. In the post-test data, it was found an increasing adequacy of protein and iron. A good intake of iron needs showed the adherence of iron supplementation. Some pregnant women who had experienced insufficient energy, carbohydrates and vitamin $\mathrm{C}$ would have a risk of anemia. This is supported by the results of related research that women with anemia show a low adequacy in energy, protein, folate, B12, iron, vitamin $\mathrm{C}$ and red meat (Thomson et al., 2011). Related research stated that there were several factors that influence the nutrition 
intake of pregnant mothers, namely gestational age, education, and family income (Wang et al., 2015). In this study, more than $50 \%$ of respondents had secondary level of education and had income $<3$ million. This could be an obstacle for some pregnant women to be able to make changes in their nutrition intake.

Nutrition during pregnancy is very important for fetal development and long-term health in infants. Malnutrition and obesity during pregnancy may affect the condition of fetal development, growth and development of childhood and the risk of developing chronic diseases in adults (Imdad, Lassi, Salaam, \& Bhutta, 2017).

Pre-test scores on adherence to iron supplementation have a low score. Some pregnant women still stated that they had not routinely taken iron supplementation because of forgetfulness and nausea. This was supported by other studies about the causes of non-compliance of iron tablets in pregnant women, which are access to iron tablets, forms of vitamins, side effects, fear, forgetful behavior and feeling no need (Galloway et al., 2002).

Post-test scores on adherence to iron supplementation increased after the intervention. To improve adherence to iron supplementation in this study, a mother was given a monitoring card for iron supplement. Families who have received health education about prevention of anemia may help monitor the regularity of pregnant women in taking iron supplements. Material about preventing anemia was also given to families so that they understood the importance of preventing anemia for pregnant women and provided support.

In this intervention, the adherence to iron supplementation was also improved by providing information about the community's inappropriate perception of iron supplements. Some inappropriate perception of iron supplements might cause obese babies and babies with disability, high blood pressure, or iron tablets consumed only when having health complaints. The correct understanding about wrong perceptions will increase compliance in taking iron supplements. A way to minimize forgetfulness in taking iron supplements is by increasing support of the family by reminding pregnant women to take iron tablets regularly. Families also need to monitor whether pregnant mothers have taken iron tablets properly. To improve the family's ability to provide the support, this intervention also provides health education to families about prevention of anemia in pregnancy. The form of family support for pregnant mothers can be in the form of information support, emotional support, and instrumental support. Information support can be provided by reminding pregnant women to take iron tablets regularly, have food that is nutritious and high in iron, and maintain hygiene. Giving time to listen to their complaints and giving them encouragement can give emotional support. Instrumental support can be given by giving them direct support, such as helping them with homework.
Most pregnant women had regularly taken iron supplementation of one tablet per day, but there were still many of them consumed it in an inappropriate manner so it was not absorbed optimally. They took iron supplements before tea, coffee and milk. Some of them also did not understand that orange juice could be taken to reduce nausea after taking iron supplements. Understanding the needs of pregnant mothers should be improved through health education. Most pregnant women understood the importance of taking iron supplementation regularly, but they did not understand how to take it properly. The status of iron in the human body depends on the absorption of iron in food. Iron absorption may be increased through sources of vitamin C, such as oranges, papaya and certain animal protein sources, such as beef, chicken and fish. Vitamin C helps absorb non-heme iron by changing the shape of ferrous into ferro, which is easily absorbed. Conversely, iron absorption may be inhibited by several inhibitors, including caffeine, tannin, oxalate, and phytate, which can be found in soy products, tea and coffee (Masthalina, Laraeni, \& Dahlia, 2015).

The result of the study on the intestinal worm prevention behavior was an increase in scores in the intervention group compared to the control group, but the percentage change in scores in the intervention group was very small. On average, pregnant women have a good behavior in preventing anemia through maintaining personal and environmental hygiene. This shows that the behavior of maintaining cleanliness has become a habit of pregnant women and their family. Behavior in preventing intestinal worms is related to hemoglobin levels of pregnant mothers. This is supported by several studies. There is a significant relationship between the incidence of worm infections with low iron reserves in the body in pregnant women (Baidoo, Tay, \& Abruquah, 2010).

Prevention of intestinal worms can be done by wearing sandals when going out of the house, washing hands before eating, washing vegetables and cooking them well, cleaning the floor of the house every day, using clean water for daily drinking purposes, and using a toilet to defecate. At present, there is no worm-screening program for pregnant mothers, so it will be difficult to know whether they have worms or not. Taking precautions against intestinal worms are the best thing to anticipate worms in pregnant mothers.

In the results of research on hemoglobin in pregnant mothers, there were significant differences between before and after intervention in the treatment group. The difference in hemoglobin value in the treatment group was 0.68 during the 3-month intervention in pregnant mothers. There are many factors that may affect hemoglobin levels, so it's quite difficult to get a large enough increase. Iron reserves in the body are affected by the absorption and loss of iron. Iron absorption is affected by food intake, while iron loss is affected by menstruation, pathological factors and worm conditions (Sharma \& Shankar, 
2010). This is supported by the results of research related to nutritional interventions that increase hemoglobin levels in pregnant women in the 2 nd to 3rd trimester by 0.35 points (Al-tell, El-guindi, Soliman, \& El-Nana, 2010).

The study showed that the Health Promotion Model and Self Determination Theory-based intervention may improve anemia prevention behaviors and hemoglobin level. According to Self Determination Theory (SDT), the expected behavior will be able to last longer if the patient is able to internalize the values and get satisfaction with the fulfilment of the three psychological needs in health services, autonomy, competence, and relatedness (Gebremedhin, Samuel, Mamo, Moges, \& Assefa, 2014). SDT theory is a framework in health services that focuses on patient care (Podlog \& Brown, 2016). In this study, SDT was applied to increase the commitment of pregnant women to implement anemia prevention behaviors. Increased autonomy was given by achieving the freedom to prevent anemia in accordance with the wishes and abilities possessed. Competency enhancement was given by providing health education to improve perceptions of benefits and reduce perceptions of barriers among pregnant mothers. Increased attachments were given with the involvement of families, health professionals and groups in providing support to pregnant mothers. The Health Promotion Model theory is used to predict factors that influence health behavior, which, in this case, emphasizes that health behavior may be influenced by the commitment of pregnant mothers (Pender, 2011). This intervention might identify the commitment of pregnant women and the factors that influence them in carrying out anemia prevention behavior.

Obstacle perceptions will be experienced by pregnant women in carrying out anemia prevention behaviors, both in terms of nutrition fulfilment, compliance with taking iron tablets, and prevention of intestinal worms. Barriers perceived by the mother will reduce the behavior of pregnant women in preventing anemia, so this intervention also aims to provide understanding to pregnant women about the obstacles that can be found in the prevention of anemia and efforts that can be done to overcome them. Obstacles that women feel in preventing anemia include nutritious foods that are expensive, iron tablets can cause nausea, iron tablets that must be taken every day during pregnancy cause boredom and forgetfulness, and washing hands and using footwear when going out is a nuisance.

This intervention emphasized the selfdetermination of pregnant women in carrying out anemia prevention behaviors. Health education delivered to pregnant women to increase selfdetermination was to explain three psychological needs of pregnant women, namely (1) autonomy or feeling free in carrying out pregnancy care, being free in making their own choices and decisions to take anemia prevention measures; (2) competence or feeling confident that they were able to prevent anemia by increasing their knowledge; and (3) relatedness or feeling close to family, friends and health professionals.

The limitation of this study is that the selection of respondents did not address the condition of other chronic infections that can influence hemoglobin levels in pregnant women. The recommendation in future study is to examine serum transferrin to determine the condition of anemia in pregnant women.

\section{CONCLUSION}

Interventions based on HPM and SDT influenced the anemia prevention behavior and hemoglobin level. This intervention involves pregnant women, peer group and families. Increased understanding of anemia will increase support, which strengthens selfdetermination in pregnant women. Selfdetermination of pregnant women can strengthen commitment to prevent anemia. Behavior to prevent anemia includes consumption patterns, adherence to taking iron supplements, and prevention of intestinal worms. Consumption patterns include consumption of energy, carbohydrates, protein, vitamin $\mathrm{C}$ and iron. Efforts to prevent anemia through these three things carried out simultaneously will be able to increase the hemoglobin level of pregnant mothers. Health workers can implement interventions based on HPM and STD in an effort to increase the determination of pregnant women to strengthen commitments in anemia prevention behavior. Health education provided to pregnant women also needs to involve peer groups and families so that they can provide support.

\section{REFERENCES}

Aboye, W., Berhe, T., Birhane, T., \& Gerensea, H. (2018). Prevalence and associated factors of low birth weight in Axum town, Tigray, North Ethiopia. BMC Research Notes, 11(1), 684. https://doi.org/10.1186/s13104-018-3801-z

Al-tell, M. A., El-guindi, F. K., Soliman, N. M., \& El-Nana, H. (2010). Effect of Nutritional Interventions on Anemic Pregnant Women' s Health Using Health Promotion Model. Medical Journal of Cairo University, 78(2), 109-118.

Baidoo, S. E., Tay, S. C. K., \& Abruquah, H. H. (2010). Intestinal helminth infection and anaemia during pregnancy: A community based study in Ghana. African Journal of Microbiology Research, 4(16),

1713-1718. https://doi.org/10.1080/0964056070140207 5

Dehdari, T., Rahimi, T., Aryaeian, N., \& Gohari, M. R. (2013). Effect of nutrition education intervention based on Pender ' $s$ Health Promotion Model in improving the frequency and nutrient intake of breakfast consumption among female Iranian students. Public Health 
Nutrition, 17(3), 657-666. https://doi.org/10.1017/S136898001300004 9

Fuseini, G., Edoh, D., Kalifa, B. G., Hamid, A.-W., \& Knight, D. (2010). Parasitic infections and anaemia during pregnancy in the KassenaNankana district of Northern Ghana. Journal of Public Health and Epidemiology, 2(3), 48-52.

Galloway, R., Dusch, E., Elder, L., Achadi, E., Grajeda, R., Hurtado, E., ... Stephen, C. (2002). Women's perceptions of iron deficiency and anemia prevention and control in eight developing countries. Social Science \& Medicine, 55(4), 529544. https://doi.org/10.1016/S02779536(01)00185-X

Gebremedhin, S., Samuel, A., Mamo, G., Moges, T., \& Assefa, T. (2014). Coverage, compliance and factors associated with utilization of iron supplementation during pregnancy in eight rural districts of Ethiopia: a cross-sectional study. BMC Public Health, 14(1), 1-8. https://doi.org/10.1186/1471-2458-14-607

Hameed, H., Hameed, A., Bashir, S., Akram, S., Arshad, M., \& Afzal, R. (2018). Study of Prevalence of Anaemia among Pregnant Women and Its Correlation with Different Risk Factors Drug Designing : Open Access. Drug Designing, 7(1), 1-5. https://doi.org/10.4172/21690138.1000158

Huang, L., Purvarshi, G., Wang, S., Zhong, L., \& Tang, H. (2015). The Influence of Iron-deficiency Anemia during the Pregnancy on Preterm Birth and Birth Weight in South China. Journal of Food and Nutrition Research, 3(9), 570-574. https://doi.org/10.12691/jfnr-3-9-2

Imdad, A., Lassi, Z., Salaam, R., \& Bhutta, Z. A. (2017). Prenatal Nutrition and Nutrition in Pregnancy: Effects on Long-Term Growth and Development. Early Nutrition and Long-Term Health, 3-24. https://doi.org/10.1016/B978-008-100168-4.00001-X

Kiboi, W., Kimiywe, J., \& Chege, P. (2017). Determinants of dietary diversity among pregnant women in Laikipia County, Kenya: a cross-sectional study. BMC Nutrition, 3(1), 12. https://doi.org/10.1186/s40795-017-0126-6

Masthalina, H., Laraeni, Y., \& Dahlia, Y. P. (2015). Pola Konsumsi (Faktor Inhibitor Dan Enhancer Fe) Terhadap Status Anemia Remaja Putri. Jurnal Kesehatan Masyarakat, 11(1), 80-86. Retrieved from

http://journal.unnes.ac.id/nju/index.php/kem as\%0Ahttp://dx.doi.org/10.15294/

Ministry of Health. (2013). Permenkes No 75 Tahun 2013 Tentang Angka kecukupan gizi yang dianjurkan bagi bangsa Indonesia.

Ministry of Health. (2014). PMK No. 88 iron supplementation. Kemenkes 2014, (1), 1-5. https://doi.org/10.1007/s13398-014-01737.2

Ministry of Health. (2018). Indonesia Basic Health Research 2018.

Patrick, H., \& Williams, G. C. (2012). Selfdetermination theory: Its application to health behavior and complementarity with motivational interviewing. International Journal of Behavioral Nutrition and Physical Activity, 9(1), 18. https://doi.org/10.1186/1479-58689-18

Pebri, V., Thongpat, S., \& Nitirat, P. (2018). Predictors of health-promoting behaviour among older adults with hypertension in Indonesia. International Journal of Nursing Sciences, 5(2), 201-205.

https://doi.org/10.1016/j.ijnss.2018.04.002

Pedreño, N. B., Ferriz-morel, R., Rivas, S., Almagro, B., Cervelló, E., \& Moreno-murcia, J. A. (2015). Sport commitment in adolescent soccer players Compromisso desportivo em atletas de futebol adolescentes, 11, 3-14.

Pender, N. J. (2011). Heath Promotion Model Manual. Chicago: University of Michigan.

Podlog, L. W., \& Brown, L. W. (2016). Selfdetermination theory: A framework for enhancing patient-centered care. The Journal for Nurse Practitioners, 12(8), 1-4. https://doi.org/10.1016/j.nurpra.2016.04.022

Ryan, R. M., Patrick, H., Deci, E. L., \& Williams, G. C. (2008). original article Facilitating health behaviour change and its maintenance: Interventions based on Self-Determination Theory. The European Health Psychologist, 10(March).

Shahroodi, M. V., \& Amin-shokravi, F. (2013). A Survey on the effects of the Pender' $s$ health promotion model on prediction of the employees ' physical activity. Health Education \& Health Promotion (HEHP), 1(1), 51-66.

Sharma, J. B., \& Shankar, M. (2010). Anemia in Pregnancy. JIMSA, 23(4), 253-260.

Singal, Setia, Taneja, \& Singal. (2018). Factors associated with maternal anaemia among pregnant women in rural India. Bangladesh Journal of Medical Science, 17(04), 583-592. https://doi.org/DOI:

http://dx.doi.org/10.3329/bjms.v17i4.38320 Introduction

Singh, M. B., Fotedar, R., \& Lakshminarayana, J. (2009). Micronutrient deficiency status among women of desert areas of western Rajasthan, India. Public Health Nutrition, 12(5), 624-629. https://doi.org/10.1017/S136898000800239 5 


\section{TRIHARINI ET AL.}

Susiloningtyas, I. (2012). PEMBERIAN ZAT BESI (Fe) DALAM KEHAMILAN Oleh: Is Susiloningtyas. Majalah Ilmiah Sultan Agung, 50, 128.

Taye, B., Abeje, G., \& Mekonen, A. (2015). Factors associated with compliance of prenatal iron folate supplementation among women in Mecha district, Western Amhara: A cross-sectional study. Pan African Medical Journal, 20, 1-7. https://doi.org/10.11604/pamj.2015.20.43.48 94

Thomson, C. A., Stanaway, J. D., Neuhouser, M. L., Snetselaar, L. G., Stefanick, M. L., Arendell, L., \& Chen, Z. (2011). Nutrient Intake and Anemia Risk in the Women's Health Initiative Observational Study. Journal of the American Dietetic Association, 111(4), 532-541. https://doi.org/10.1016/j.jada.2011.01.017

Triharini, M., Nursalam, Sulistyono, A., Adriani, M., Armini, N. K. A., \& Nastiti, A. A. (2018). Adherence to iron supplementation amongst pregnant mothers in Surabaya, Indonesia:
Perceived benefits, barriers and family support. International Journal of Nursing Sciences, 5(3), 243-248.

https://doi.org/10.1016/j.ijnss.2018.07.002

Wang, P.-Y., Liu, F.-L., Zhang, Y.-M., Parés, G., Reidy, K., Zhao, W.-Z., ... Zheng, Y.-D. (2015). Nutrient Intakes of Pregnant Women and their Associated Factors in Eight Cities of China: A Cross-sectional Study. Chinese Medical Journal, 128(13), 1778. https://doi.org/10.4103/03666999.159354

WHO. (2008). Worldwide prevalence of anaemia 19932005: WHO global database on anaemia.

Yetunde, S.-L. M., \& Olubukunola, O. (2015). The nutrient adequacy of foods eaten by pregnant women attending antenatal clinic at traditional birth homes. IOSR Journal of Nursing and Health Science Ver. III, 4(2), 2320-1940. https://doi.org/10.9790/1959-04236567 